\title{
Complement in Hemolysis- and Thrombosis- Related Diseases
}

\author{
Shanshan Luo ${ }^{1}$, Desheng Hu ${ }^{1,2}$, Moran Wang ${ }^{1}$, Peter F. Zipfel ${ }^{3,4 *}$ and $\mathrm{Yu} \mathrm{Hu}{ }^{1 *}$ \\ ${ }^{1}$ Institute of Hematology, Union Hospital, Tongji Medical College, Huazhong University of Science and Technology, Wuhan, \\ China, ${ }^{2}$ Department of Integrated Traditional Chinese and Western Medicine, Union Hospital, Tongji Medical College, \\ Huazhong University of Science and Technology, Wuhan, China, ${ }^{3}$ Department of Infection Biology, Leibniz Institute for \\ Natural Product Research and Infection Biology, Hans Knöll Institute, Jena, Germany, ${ }^{4}$ Friedrich Schiller University, Faculty of \\ Biological Sciences, Jena, Germany
}

The complement system, originally classified as part of innate immunity, is a tightly self-regulated system consisting of liquid phase, cell surface, and intracellular proteins. In the blood circulation, the complement system, platelets, coagulation system, and fibrinolysis system form a close and complex network. They activate and regulate each other and jointly mediate immune monitoring and tissue homeostasis. The dysregulation of each cascade system results in clinical manifestations and the progression of different diseases, such as sepsis, atypical hemolytic uremic syndrome, C3 glomerulonephritis, systemic lupus erythematosus, or ischemia-reperfusion injury. In this review, we

OPEN ACCESS

Edited by:

Cordula M. Stover,

University of Leicester,

United Kingdom

Reviewed by:

Damien Noone,

Hospital for Sick Children, Canada

Péter Gál,

Hungarian Academy of Sciences

(MTA), Hungary

*Correspondence:

Peter F. Zipfel

peter.zipfe/@/eibniz-hki.de

Yu Hu

dr_huyu@126.com

Specialty section:

This article was submitted to

Molecular Innate Immunity,

a section of the journal

Frontiers in Immunology

Received: 13 September 2019

Accepted: 15 May 2020

Published: 10 July 2020

Citation:

Luo S, Hu D, Wang M, Zipfel PF and Hu Y (2020) Complement in Hemolysis- and Thrombosis- Related

Diseases. Front. Immunol. 11:1212. doi: 10.3389/fimmu.2020.01212 summarize the crosstalk between the complement system, platelets, and coagulation, provide integrative insights into how complement dysfunction leads to hemopathic progression, and further discuss the therapeutic relevance of complement in hemolytic and thrombotic diseases.

Keywords: complement, hematological disorder, anti-complement agent, platelet, hematology

\section{INTRODUCTION}

The complement system is an ancient and critical effector mechanism of the innate immune system, which consists of central components of the whole cascade (C1 to C9), regulators and inhibitors, proteases and newly assembled enzymes, multiple activation products, and receptors for complement components and their products (1). Based on the different mechanisms for its initiation, the complement system is classified into three pathways (the alternative, lectin, and classical pathways, short as CP, LP, AP) that merge at the level of C3 cleavage. Being a central immune surveillance system, complement can be activated within seconds upon infection or stimulation. Complement activation leads to the generation of anaphylactic peptides, cytolytic compounds, and antimicrobial compounds. These generated molecules in turn activate proinflammatory mediators and recruit effector cells, thereby providing an immediately acting barrier against invading microbes or modified self-cells, including tumor cells, in a self-controlling manner $(2,3)$. In addition, complement also functions in regulation of adaptive immunity, mediation of cell integrity, and tissue homeostasis (4).

Apart from the complement cascade, the coagulation and the fibrinolytic systems are also enzymatic cascades existing in the blood. The coagulation cascade and fibrinolytic system plus platelets compromise the hemostasis system (5). Hemostasis is classically defined as the cessation of bleeding in the body and takes place in a highly organized and time-dependent manner at the site of vascular injury. The coagulation cascade comprises the intrinsic pathway and the extrinsic pathway. Activation of coagulation cascade via each pathway leads to fibrin formation. Platelets, also called "thrombocytes," have no nucleus and are fragments of the cytoplasm derived from 
the megakaryocytes of the bone marrow that enter the blood circulation (6). Platelets have a major function in repairing vascular damage and stopping acute bleeding. When the endothelium is broken, platelets are immediately activated by different factors, such as collagen and tissue factors (7). The activated platelets and fibrin are then cross-linked together via GpIIbIIIa, forming thrombus. Meanwhile, platelets also contribute to thrombus formation in atherosclerosis, venous thrombosis, myocardial infarction, disseminated intravascular coagulation (DIC), and many other pathological conditions.

An expanding body of evidence suggests multiple interactions between the hemostatic system and innate immunity exist, especially the complement system. Both systems consist of fluid phase factors distributed in the blood, in which these factors form a close network, interact with each other, tightly self-regulate, and mediate immune surveillance and tissue homeostasis (8). However, the dysregulation of any component in both systems results in pathological conditions and clinical manifestations of the diseases with critical thrombotic or inflammatory complications, such as sepsis, systemic lupus erythematosus, or ischemia-reperfusion injury (9).

In this review, we first give an overview of the close interaction between complement and hemostatic networks, then provide a deep insight into the roles of complement in hematologic disorders and further discuss current complementbased immunotherapy in treating such disorders. This overview is crucial in understanding hemopathic pathology and guiding the development of complement-based diagnostic tools and valuable therapies to improve the clinical management of patients with hemopathic conditions.

\section{THE CROSSTALK BETWEEN COMPLEMENT AND HEMOSTASIS}

The complement system is genetically derived from the serine protease reaction cascade encoded by the same ancestor gene as coagulation factors. In blood circulation, complement forms close networks with not only platelets but also the coagulation and fibrinolytic systems, participating in a wide range of biological functions. The common roles of these systems are to present the first defense line against infectious microbes that enter the bloodstream and blood circulation, to initiate repairment after tissue damage, and to cause adverse reactions either maintaining homostasis or resulting in severe disorders (10). In this part, we summarize the interaction network between complement, platelets, and coagulation cascade.

Abbreviations: TCC, terminal complement complex; AP, alternative pathway; LP, lectin pathway; CP, classical pathway; C3, complement factor 3; ITP, idiopathic thrombocytopenic purpura; HUS, hemolytic uraemic syndrome; aHUS, atypical hemolytic uremic syndrome; $\mathrm{PNH}$, paroxysmal nocturnal hemoglobinuria; MASP2, mannose-binding lectin-associated serine protease 2; AIHA, autoimmune hemolytic anemia; CAD, cold agglutinin disease; CAS, secondary cold agglutinin syndrome; $\mathrm{PCH}$, paroxysmal cold hemoglobinuria; DIC, disseminated intravascular coagulation.

\section{The Interplay Between Complement and Platelets}

Hamad et al. reported that the complement system activated platelets in various ways, while thrombinactivated platelets in turn activated complement cascade, which forms a potential self-strengthening cycle (10), indicating a close interplay between the complement system and platelets.

\section{The Effect of the Complement System on Platelet Activation}

An early in vitro report showed that thrombin-mediated platelet aggregation and serotonin secretion are highly enhanced by the combination of $\mathrm{C} 3$ and terminal complement complex (TCC). In this process, Polley et al. found that thrombin associated with the platelet membrane presumably initiated C3 convertase formation in a way different from the known classic or alternative mechanisms. The formed C3 convertase entered the known complement sequence at the $\mathrm{C} 3$ stage and proceeded to activate the terminal components through C5 to $\mathrm{C}$, which may enhance the uptake of the C3 and TCC complex by platelets. In turn, the activated complement system on the platelet surface, as a combination of C3 and TCC, highly enhanced platelet aggregation and serotonin secretion $(11,12)$. Another report showed that TCC induced membrane microparticle formation, thereby exposing the binding sites for factor $\mathrm{Va}$ and serving as a basis for the proteolytic generation of thrombin (13). Furthermore, both in vivo and in vitro data have shown that TCC-mediated stimulation of platelets causes transient membrane depolarization (14), granule secretion (15), induction of phosphatidylserine, and plateletcatalyzed thrombin generation, affecting platelet activation and coagulation initiation $(13,16,17)$ (Figure 1). In addition, Koelm et al. reported that surface-bound C1q, by interacting with the von Willebrand factor (VWF), induced platelet rolling (18). C1q was also shown to bind $\mathrm{gClqR} / \mathrm{p} 33$ or $\mathrm{gClqR}$ on platelet surfaces, thereby initiating platelet activation, a process that can further induce the aggregation of platelets via a Pselectin-dependent pathway (19-21). In vivo data showed that $\mathrm{C} 3$, independently of TCC formation, played specific roles in platelet activation. $\mathrm{C}^{-/-}$mice have prolonged bleeding time and diminished platelet activation, further proving a direct link between complement and platelet activation $(22,23)$. Besides, the anaphylatoxin $\mathrm{C} 3 \mathrm{a}$ and its derivative C3adesArg directly induced platelet activation and aggregation (24). In comparison to $C 3^{-/-}$mice, $\mathrm{C5}^{-/-}$mice have no apparent defect in platelet activation, platelet deposition in the vessel wall, and the initial hemostasis (22).

\section{The Effect of Platelets on Complement Activation}

Apart from the above-mentioned effects of complement on platelet activation, platelets also initiate/regulate complement activation via different secreted or surface-expressed factors. As for initiating complement activation, platelet-expressed Pselectin activates complement either on its own or by fixing C3b from spontaneous basal plasmatic C3 cleavage (25-27). Further platelets, by secreting chondroitin sulfate, bind C1q or 


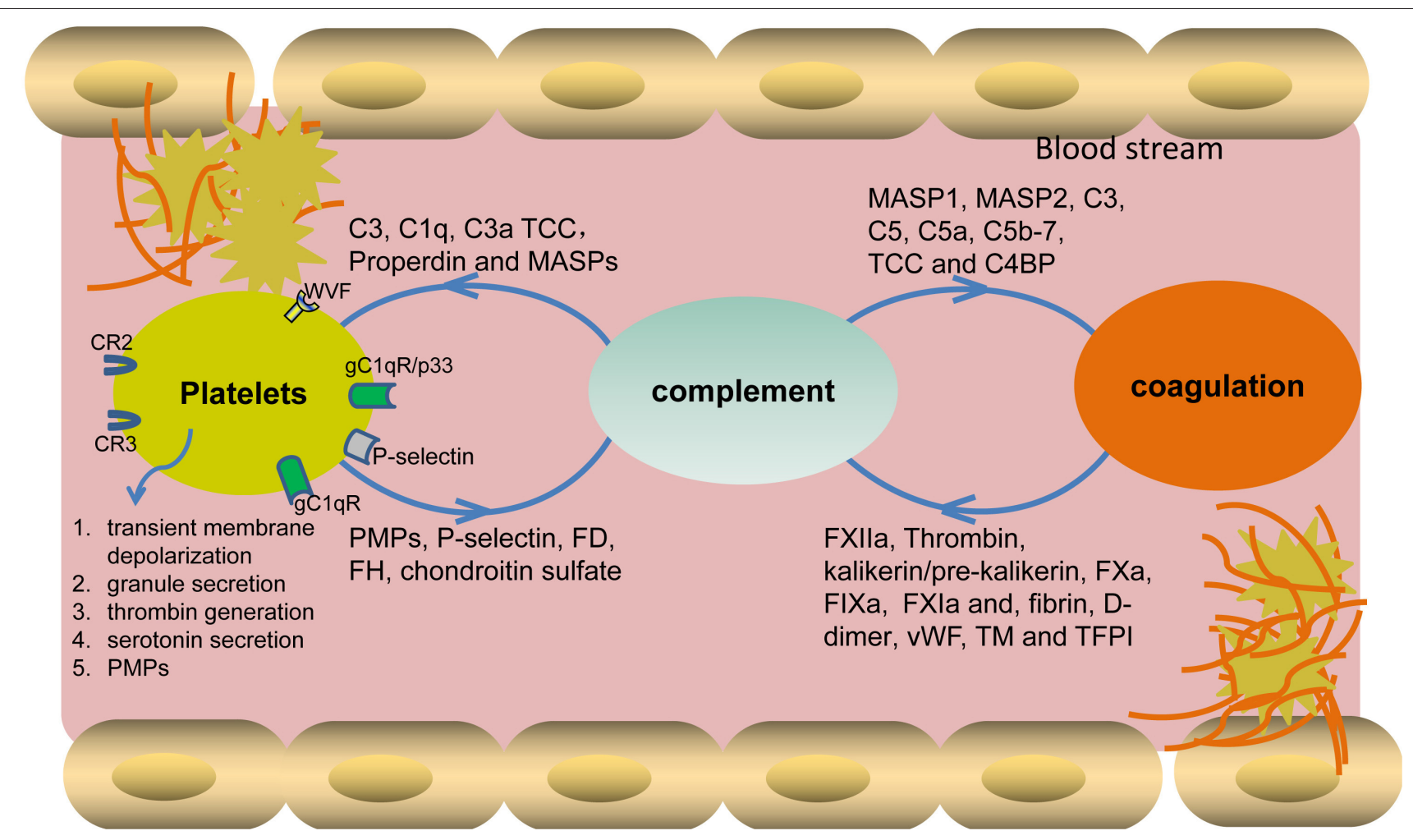

FIGURE 1 | Cross-interaction of complement with platelets and the coagulation system. Different complement components bind to platelet surface receptors and also closely interplay with coagulation factors, leading to the activation of platelets and also the initiation of coagulation cascade. In turn, the activated platelets and coagulation factors also assist complement activation by binding or interfering with different components. TCC, terminal complement complex; MASPs,

mannose-binding lectin-associated serine proteases; FD, factor D; FH, factor H; PMPs, platelet microparticles, WWF, von Willebrand factor.

factor D, thereby initiating local complement activation (28-30). As for regulating complement activation, platelets, by secreting Factor $\mathrm{H}$ from alpha-granules, either regulate $\mathrm{C} 3$ convertase activity or modulate C1q effects via CR3 (31, 32). However, contradictory data showed that Factor $\mathrm{H}$ was present throughout the cytoplasm and on the surface of normal resting platelets but with no evident concentration of Factor $\mathrm{H}$ in alpha-granules, lysosomes, or dense granules (33). In addition, platelet-expressed VWF was recently identified as a novel complement regulator that can protect endothelial cells from injury by down-regulating complement activation (34). Furthermore, a platelet, by secreting chondroitin sulfate, binds complement regulators $\mathrm{C} 1$ inhibitor (C1INH), C4b-binding protein (C4BP), and Factor $\mathrm{H}$, thereby blocking complement activation on its surface $(10,35)$.

Aside from the above-mentioned close interplay between complement and platelets, a growing body of evidence indicates that complement activation influences platelet-associated pathologies, such as idiopathic thrombocytopenic purpura (ITP) (36), atypical hemolytic uremic syndrome (aHUS) (37, 38), and paroxysmal nocturnal hemoglobinuria (PNH) $(39,40)$. Currently, such diseases are treated with anti-complement therapeutics, such as Eculizumab, H17/3E7, and TNT003, controlling the pathophysiological processes that are driven by complement over-activation (details will be discussed further in section Therapeutic Relevance of the Complement System).

\section{The Interplay Between Complement and Coagulation}

The complement and coagulation cascades are evolutionarily related enzymatic cascades in blood circulation. They are linked in their activation mechanisms and influence innate immune functions following tissue injury. Early reports showed that the levels of complement activation products in normal human serum are much higher than in anti-coagulated blood, indicating the progression of complement activation upon blood clotting (41).

\section{The Effect of the Complement System on Coagulation Cascade}

The complement system activates coagulation cascade via multiple factors (Figure 1). In vitro data showed that activated MASP-1 cleaved fibrinogen, fXIII, and TAFI, further promoting fibrin cross-linking $(42,43)$, while MASP-2 participated in the activation of thrombin and the subsequent generation of fibrin (44). Further, the complement activation products C5a and TCC trigger tissue factor expression and activation in both human endothelial cells and neutrophils, which results in the activation of the extrinsic coagulation pathway $(45,46)$. C5a was also shown to induce the up-regulation of PAI-1, thereby promoting a local procoagulant effect on mast cells $(47,48)$. Additionally, TCC can cause an increase of blood 
thrombogenicity by simultaneously inducing procoagulant and antifibrinolytic proteins and inhibiting natural anticoagulants $(49,50)$. Besides the above-mentioned roles of the complement activation products, the complement regulators also display obvious effects on coagulation. For example, $\mathrm{C} 4 \mathrm{~b}$ binding protein (C4BP), by binding to protein $\mathrm{S}$, affects natural anticoagulation in vitro (51). Another complement regulator, C1 inhibitor, also shows an inhibitory effect on the activity of fXIIa, fXIa, and kallikrein in the coagulation system (52-54). Importantly, Subramaniam et al., by using an in vivo mouse model, showed that $\mathrm{C}^{-/-}$and $\mathrm{C} 3^{-/-}$mice had longer tail bleeding times and were less susceptible to thrombosis, further proving that complement plays important roles in the progression of coagulation (22).

\section{The Effect of Coagulation Cascade on Complement Activation}

The interplay between complement and coagulation cascades occurs in both directions. The coagulation factors can also activate complement cascade at different levels. For the initiation of complement activation, Factor XII binds to the complement $\mathrm{C} 1$ or the globular $\mathrm{C} 1 \mathrm{q}$ receptor (gC1qR), initiating $\mathrm{CP}$ activation $(55,56)$. Fibrin and the plasmin-generated fibrin fragment (Ddimer) in plasma bind and activate MASP-1 and MASP-2, leading to LP activation. Furthermore, pre-kallikrein cleaves Factor B and activates $\mathrm{C} 1$ s, thereby activating both $\mathrm{AP}$ and $\mathrm{CP}$ (57). In terms of $\mathrm{C} 3$ activation, the interaction of fibrinogen/fibrin with the MASPs also modulates the activation of $\mathrm{C} 3$ and $\mathrm{C} 4$, as well as the surface deposition of $\mathrm{C} 3 \mathrm{~b}$ and $\mathrm{C} 4 \mathrm{~b}$ (58). Meanwhile, kallikrein can cleave not only complement factor B but also C3 and C5 $(53,59,60)$. Also, on the C5 level, in vivo data showed that thrombin cleaved C5 in the absence of C3 (61). Further investigation revealed that, besides thrombin, several other factors (i.e., FIXa, FXa, FXIa, and plasmin) can also cleave $\mathrm{C} 3$ and C5, leading to C3a and C5a generation, respectively. What is more, thrombomodulin and tissue-factor pathway inhibitor participate in complement regulation (62-65).

Besides the above-mentioned two-way interplay between the coagulation and complement cascades, NETosis appears to be a third important player involved in the complement-coagulation interaction, forming a triangular relationship to protect the host against pathogens. Activated complement proteins stimulate NET formation, and NETs, in turn, serve as a platform for complement activation. Furthermore, NETs act as a scaffold for thrombus formation during coagulation (66). Taken together, all of the close interplay between coagulation and complement explains why the association of both systems with several clinical inflammatory and thrombotic conditions exists.

\section{COMPLEMENT IN HEMOLYTIC AND THROMBOTIC DISEASES}

Complement activation plays an essential role in controlling infection and maintaining homeostasis, whereas complement dysfunction is associated with the pathogenesis of multiple hemolytic and thrombotic diseases (Figure 2). Cross-interplay of the complement and hemostatic systems could be a key mediator of "thrombo-inflammation" (67). Abundant evidence demonstrated that complement hyperactivation is correlated with thrombosis and the development of multiple organ failures. This section aims to provide an integrative overview of the mechanisms underlying the interactions between complement and hemostasis in disease pathology.

\section{Complement in Autoimmune Hemolytic Anemia}

Autoimmune hemolytic anemia (AIHA) is a collective term for several diseases. It is characterized by autoantibody-mediated destruction of red blood cells. Complement activation in AIHA may exacerbate extravascular hemolysis and may also occasionally result in intravascular hemolysis. In particular, the subgroup primary cold agglutinin disease (CAD), secondary cold agglutinin syndrome (CAS), and paroxysmal cold hemoglobinuria $(\mathrm{PCH})$ are entirely complement-dependent disorders, whereas warm-antibody AIHA is only partially related to complement activation (68).

In $\mathrm{CAD}$, autoimmune disorders are often associated with CP hyperactivation (69). The major subtype of cold agglutinin (CA) is the IgM subtype, which accounts for $90 \%$ of the total cases (29). IgM binds to erythrocytes at the end of circulating limbs and then activates CP, resulting in C3 cleavage (30). When returned to the central part of the circulation with a body temperature of $37^{\circ} \mathrm{C}$, IgM becomes dissociated from the cell surface, but $\mathrm{C} 3 \mathrm{~b}$ remains bound to red blood cells. These C3b opsonized red blood cells bind to complement receptors on systemic macrophages. Afterwards, they are cleared in the liver to mediate extravascular hemolysis. In homeostatic conditions, the expression of complement regulators CD55 and CD59 on erythrocyte membranes blocks complement activation and protects the erythrocytes from lysis. However, in severe conditions with infection, surgery and autoimmune diseases, intravascular hemolysis caused by the over-activation of TP may occur due to the dysfunction of these two surfaceexpressed regulators $(28,70)$. Current therapy for IgM-mediated autoimmune hemolytic anemia mainly aims to decrease autoantibody production. However, most of these treatments require time to become effective and also will neither stop immediately ongoing complement-mediated hemolysis nor prevent hemolysis of transfused red blood cells. Therefore, direct inhibition of the complement system might be a suitable approach to halt or at least attenuate ongoing hemolysis, which helps to improve the recovery of red blood cell transfusion in autoimmune hemolytic anemia. In recent years, several complement inhibitors have become available in the clinic with proven efficacy in autoimmune hemolytic anemia, which will be discussed in section Therapeutic Relevance of the Complement System.

CAS is different from CAD in terms of etiology and the locality of B cells, but it is characterized by the same complementdependent hemolysis mechanism (71). Furthermore, the hemolysis of PCH is entirely complement-dependent. Polyclonal IgG antibodies bind to the $\mathrm{P}$ antigen on the erythrocyte surface but do not agglutinate erythrocytes. This P-antigen-antibody 


\section{Disease conditions}

\section{Hemolytic and thrombotic} related diseases

1. Dysfunction of CD55 and CD59 caused CAD, CAS and PCH;

2. Over activation of complement and platelets leads to DIC

3. Absence of CD55 and CD59 on platelet surface leads to $\mathbf{P N H}$,

4. Mutations in $\mathrm{FH}, \mathrm{CD} 46, \mathrm{FI}$ and C3, or deletion of FHR1, FHR3 and FHR4 lead to aHUS.

\section{Homeostatic condidtions}

complement regulators

Proper function of complement regulators control complement over activation, protect the self cells from lysis.

1. Classical and lectin pathway inhibitors: C1INH, C4BP, CD46, CD55,

2. Alternative pathway inhibitors: Factor $\mathrm{H}$, FHL-1, CD46 and CD55;

3. Terminal pathway inhibitors: CD59, CFHR-1, Vitronectin and clusterin

FIGURE 2 | Link between complement and hematological disorders. Complement, on the one hand, can protect the host from infection and maintain body homeostatic conditions, and, on the other hand, it may also cause hematological disorders due to uncontrolled activation or utilization of complement regulators. C1INH, C1 inhibitor; FHL-1, factor H-like protein 1; C4BP, C4 binding protein; AP, alternative pathway; CP, classical pathway; LP, lectin pathway; TP, terminal pathway; CFHR1, complement factor $\mathrm{H}$ related protein 1; TCC, terminal complement complex; MASPs, mannose-binding lectin-associated serine proteases; FB, factor B; FD, factor D; FP, factor P.

complex is a very strong complement activator, which leads to complete over-activation of $\mathrm{CP}$ and $\mathrm{TP}$, mediates massive intravascular and extravascular hemolysis, and causes sudden onset of the disease.

In contrast, auto-antibodies to warm-AIHA (w-AIHA) mostly belong to the IgG class (72). In up to $50 \%$ of w-AIHA, a direct antiglobulin test is positive for complement fragments, and the most common one is C3d (73). Another autoimmune disease characterized by platelet destruction and thrombocytopenia is immune thrombocytopenia purpura (ITP) (74). Thrombocyte destruction in ITP is mediated by multiple immune mechanisms. Interestingly, some ITP patients have increased complement activation, indicating that complement also takes part in ITP progression. However, how the complement system interferes with ITP progression remains unclear.

\section{Complement in Disseminated Intravascular Coagulation}

Disseminated intravascular coagulation (DIC) is characterized by an increased incidence of thrombin formation or hemorrhagic diathesis due to the consumption of platelets and coagulation proteins in the circulation. The most common cause of DIC is sepsis, being characterized by an over activation of complement and platelet activation. Others reported that mannose-binding lectin (MBL) and/or MASP-1/3 were involved with hemostasis following injury. Staphylococcus aureus-infected MBL null mice developed DIC with the characteristic of elevated IL-6 levels in blood. Infected MBL null mice also developed liver injury, suggesting that MBL deficiency may develop into DIC and organ failure during infectious diseases (75). Furthermore, Zhao et al. reported, on the basis of 276 patient samples, that the complement components were modified in sepsis patients with DIC. The statistical data showed that C3, TCC, and MBL were significantly increased in septic patients with DIC (76).

\section{Complement in Paroxysmal Nocturnal Hemoglobinuria}

Paroxysmal nocturnal hemoglobinuria $(\mathrm{PNH})$ is an acquired syndrome characterized by intravascular hemolysis, thrombosis, and bone marrow failure (77). Thrombosis is the most urgent indication for therapies and the leading cause of $\mathrm{PNH}$ death. The reasons for the thrombosis tendency in $\mathrm{PNH}$ are multifactorial. The absence of two glycosylphosphatidylinositolanchored complement surface proteins, CD55 and CD59, on the platelet's surface of $\mathrm{PNH}$ patients leads to the formation of prethrombotic particles. CD55 regulates the formation of C3 and $\mathrm{C} 5$ convertases by binding to $\mathrm{C} 3 \mathrm{~b}$ and $\mathrm{C} 4 \mathrm{~b}$ and preventing the amplification of complement cascade, while CD59 prevents C9 polymerization and TCC formation. The absence of these two regulators leads to uncontrolled complement activation and lysis of the cell membrane, which accounts for hemolysis and other PNH manifestations (78).

Meanwhile, C5a was clearly shown to induce inflammation and thrombosis by inducing the release of inflammatory cytokines, such as IL-6, IL-8, and TNF $\alpha$ (46). Furthermore, Fibach et al. show that oxidative stress, in conjunction with activated complement, may cause the underlying symptoms of PNHs, such as intra- and extravascular hemolysis and thrombotic complications. Besides dysfunction of the complement system, other deficiencies such as in heparin sulfate and GPI-anchored common receptor are also presumed to favor thrombosis in PNH $(79,80)$. However, it is not clear which mechanism has the 
greatest impact on PNH thrombosis. Currently, the most effective strategy to prevent $\mathrm{PNH}$ thrombosis is complement inhibition on TP (81). Eculizumab is indicated for the treatment of acute thromboembolic events.

\section{Complement in Atypical Hemolytic Uremic Syndrome}

Atypical hemolytic uremic syndrome (aHUS) is a type of thrombotic microangiopathy characterized by glomerular endothelial damage, thrombosis, and mechanical hemolysis. Both genetic and acquired abnormalities of the complement system can cause aHUS progression (82). Complement activation is normally controlled by regulatory proteins, such as Factor $\mathrm{H}$ and FHL-1 in plasma and CD46 on the cell surface. Approximately $70 \%$ of patients with aHUS have mutations in genes that regulate the AP activation because the pathogenesis of aHUS is strongly correlated to the AP dysfunction (82-85). Most patients have one defective allele and one intact allele of Factor $\mathrm{H}$ (86), which occurs in the carboxy-terminal surface recognition region and leaves the complement-regulatory region of the amino-terminus intact. These heterozygous mutations of Factor $\mathrm{H}$ gene reduce its surface binding to erythrocytes, weakening the protective surface property, and thereby leading to uncontrolled complement activation. The amplified local complement activation causes erythrocyte lysis and host tissue damage. Besides the mutation of fluid-phase regulator Factor $\mathrm{H}$, heterozygous mutations of CD46 also predispose to aHUS (87). Further, mutations in factor I and C3 were identified in aHUS. In addition, Abarrategui-Garrido et al. reported that a novel genetic mutation in CFHR1 is highly associated with aHUS (88). Importantly, in aHUS patients, deletions of CFHR1, CFHR3, and CFHR4 lead to the development of Factor $\mathrm{H}$ autoantibodies (89). These autoantibodies bind to and block the C-terminal recognition region of Factor $\mathrm{H}$, leading to uncontrolled AP complement activation.

\section{THERAPEUTIC RELEVANCE OF THE COMPLEMENT SYSTEM}

In the last decade, the complement system has been increasingly focused on since its inappropriate or uncontrolled activation is closely related with many diseases, such as thrombotic and hemolytic diseases and autoimmune diseases. The application of anti-complement agents in the clinic represents a major technical achievement, suggesting a novel etiologic treatment for different human diseases (90).

Eculizumab, the first anti-complement agent, is a monoclonal antibody that binds to $\mathrm{C} 5$, interferes with $\mathrm{C} 5$ cleavage, and thereby inhibits TP activation (91). Eculizumab is approved for $\mathrm{PNH}$, aHUS, and Myastenia gravis, with potential impact on the severe clinical course. This TP inhibitor was later also proved efficacious for the treatment of severe idiopathic warm AIHA. With more and more interest in the complement therapies, different subtypes of C5 inhibitors with higher specificity were generated, such as Ravulizumab (A.LXN1210) and ALNCC5 (Table 1). Ravulizumab, being a second-generation of C5specific monoclonal antibody, provides immediate, complete, and sustained C5 inhibition. Ravulizumab binds to C5 with a higher affinity than Eculizumab, inhibiting the formation of $\mathrm{C} 5 \mathrm{a}$ and $\mathrm{C} 5 \mathrm{~b}$, thereby blocking the occurrence of complement activation and hemolysis, and achieving better readout when treating patients with PNH and aHUS (98). ALN-CC5 is another TP inhibitor that targets C5 via RNA interference. ALN-CC5 can significantly reduce the $\mathrm{C} 5$ level and inhibit complement activity. Importantly, Hill et al. reported that patients with $\mathrm{PNH}$ have good tolerance to ALN-CC5 and prolonged duration of drug efficacy (99).

However, C5 inhibitors have broad effects on the TP of the complement system, lacking specificity. Widespread inhibition of the complement cascade may jeopardize patient health due to increased susceptibility to infections. Thus, the development of pathway-specific complement inhibitors has been a longlasting goal over the past few decades. Compstatin, Compstatin 40 (Cp40), and its long-acting analog, polyethylene glycol(PEG$\mathrm{Cp} 40$ ) are newly designed complement inhibitors that display inhibition on the upstream of the complement cascade (92). Compstatin is a cyclic fibrin polypeptide composed of 13 amino acids that binds to $\mathrm{C} 3$ and $\mathrm{C} 3 \mathrm{~b}$. At present, the compstatinrelated inhibitors used for the treatment of patients with $\mathrm{PNH}$ are mainly Cp40 and PEG-Cp40 (94).

Another type of pathway-specific inhibitor is recombinant fusion protein, which includes TT30 and CRIg-L-FH/CRIg-LFH. TT30 is a $65-\mathrm{kDa}$ recombinant human fusion protein, consisting of the $\mathrm{iC} 3 \mathrm{~b} / \mathrm{C} 3 \mathrm{~d}$-binding region of complement receptor 2 and the inhibitory domain of the regulator Factor $\mathrm{H}$, that can efficiently block AP activation. Risitano et al. confirmed that TT30 completely inhibited erythrolysis in PNH patients and C3b-mediated extravascular hemolysis in a dosedependent manner (95). In addition, TT30 effectively inhibits AP-mediated $\mathrm{C} 3 \mathrm{~b}$ deposition on the erythrocyte membrane in a CR2-dependent manner, blocks the formation of TCC, and inhibits both intravascular and extravascular hemolysis of AIHA (95). CRIg-FH and CRIg-L-FH are novel CRIg-targeted complement inhibitors that are designed by connecting the functional domains of CRIg and Factor H. CRIg-L-FH is slightly more potent than CRIg-FH. Both regulators dramatically inhibited both AP- and CP-mediated hemolysis and successfully eliminated the deposition of $\mathrm{C} 3 \mathrm{~b} / \mathrm{iC} 3 \mathrm{~b}$, thereby efficiently protecting aberrant erythrocytes of $\mathrm{PNH}$ patients (96).

The third type of pathway-specific inhibitor is monoclonal antibodies, including TNT003, Sutimlimab, and H17/3E7. TNT003, as shown by Peerschke et al., is a mouse-derived monoclonal antibody that targets serine proteinase $\mathrm{C} 1 \mathrm{~s}$, inhibits complement deposition and the formation of TCC complexes, and thus prevents intravascular and extravascular hemolysis in CAD patients (69). Statistical analysis showed that when TNT003 was applied in ITP patients, plasma C4d, C3b, and C5b-9 deposition were decreased dramatically (92), suggesting a possible therapeutic effect of TNT003 on ITP. Sutimlimab, another monoclonal antibody that binds $\mathrm{C} 1 \mathrm{~s}$, quickly blocks hemolysis, corrects anemia, and eliminates the need for blood 
TABLE 1 | The main complement-related immunotherapies used in hematological disorders.

\begin{tabular}{|c|c|c|c|c|c|}
\hline Complement therapies & Targeted factors & Diseases to be treated & Readout & Molecular nature & References \\
\hline TNT003 & C1s & CAD, ITP & Higher specificity, narrow effect & Monoclonal antibody & $(69,92)$ \\
\hline Sutimlimab & C1s & CAD & Higher specificity, narrow effect & Monoclonal antibody & $(93)$ \\
\hline Cp40 & C3b, C3d & $\mathrm{PNH}$ & Higher specificity, narrow effect & Cyclic polypeptide & (94) \\
\hline PEG - Cp40 & C3b, C3d & $\mathrm{PNH}$ & Higher specificity, narrow effect & Cyclic polypeptide & (94) \\
\hline ТТЗ0 & $\mathrm{iC3b} / \mathrm{C3d}$ & $\mathrm{PNH}, \mathrm{AlHA}$ & Higher specificity, narrow effect & Fusion protein & (95) \\
\hline CRlg-L-FH & C3b/C3bi & $\mathrm{PNH}$ & Efficiently protected aberrant erythrocytes & Fusion protein & $(96)$ \\
\hline $\mathrm{CRlg}-\mathrm{FH}$ & C3b/C3bi & $\mathrm{PNH}$ & Efficiently protected aberrant erythrocytes & Fusion protein & $(96)$ \\
\hline $\mathrm{H} 17 / 3 \mathrm{E} 7$ & C3b/C3bi & $\mathrm{PNH}$ & Efficiently inhibits erythrocytes lysis & Monoclonal antibody & $(97)$ \\
\hline Eculizumab & C5 & $\mathrm{PNH}, \mathrm{aHUS}$, wAlHA & $\begin{array}{l}\text { First generation of C5 inhibitor, broad } \\
\text { effect }\end{array}$ & Monoclonal antibody & $(91)$ \\
\hline Ravulizumab & C5 & $\mathrm{PNH}, \mathrm{aHUS}$ & High affinity, better effect & Monoclonal antibody & $(98)$ \\
\hline ALN-CC5 & C5 & $\mathrm{PNH}$ & Good tolerance and long duration & siRNA & (99) \\
\hline
\end{tabular}

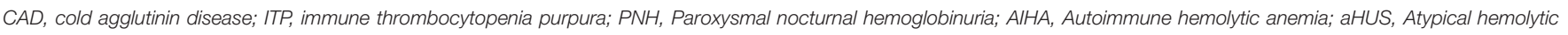
uremic syndrome. The order was classified according to the target factors of the whole complement cascade.

transfusion in patients with CAD. Based on these data, sutimlimab was given a breakthrough treatment designation by the U.S. Food and Drug Administration for treatment of this condition (93). Lindorfer et al. reported that the monoclonal antibody H17/3E7 was directed to combine with $\mathrm{C} 3 \mathrm{~b} / \mathrm{iC} 3 \mathrm{~b}$ to effectively inhibit the lysis of erythrocytes in $\mathrm{PNH}$ patients. By combining with $\mathrm{C} 3$ and $\mathrm{C} 3 \mathrm{~b}, \mathrm{H} 17 / 3 \mathrm{E} 7$ can inhibit the formation of C3 and C5 convertase, thereby effectively inhibiting AP activation, whereas CP activation is not affected (97). These inhibitors have been more and more widely used for the treatment of thrombotic and hemolytic diseases, indicating that anti-complement agents are potential therapeutic drug candidates for a range of complementmediated diseases.

\section{CONCLUDING REMARKS AND PERSPECTIVES}

A large amount of experimental and clinical evidence shows that complement closely interplays with hemostasis systems and participates in many important biological functions, while dysfunction of the complement system directly or indirectly interferes with many hemopathic progressions. Thereby, complement-related therapies have become more and more

\section{REFERENCES}

1. Ekdahl KN, Teramura Y, Hamad OA, Asif S, Duehrkop C, Fromell K, et al. Dangerous liaisons: complement, coagulation, and kallikrein/kinin cross-talk act as a linchpin in the events leading to thromboinflammation. Immunol Rev. (2016) 274:245-69. doi: 10.1111/imr.12471

2. Carroll MC. The complement system in regulation of adaptive immunity. Nat Immunol. (2004) 5:981-6. doi: 10.1038/ni1113

3. Gros P, Milder FJ, Janssen BJ. Complement driven by conformational changes. Nat Rev Immunol. (2008) 8:48-58. doi: 10.1038/nri2231

4. Zipfel PF, Skerka C. Complement regulators and inhibitory proteins. Nat Rev Immunol. (2009) 9:729-40. doi: 10.1038/nri2620 into focus. However, current existing anti-complement agents display a broad effect but lack specificities, which may increase patient susceptibility to infections due to general inhibition of the overall complement-mediated effector functions. New therapies for precisely targeting complement are on the way and are urgently needed. One of the great challenges in this aim is to clarify the disease pathogenesis and find out which complement component's dysfunction leads to hemopathic progression and how.

\section{AUTHOR CONTRIBUTIONS}

SL contributed by collecting data, designing the structure, writing, and review. $\mathrm{DH}$ contributed to collecting data and writing. MW contributed to collecting data. PZ contributed to writing, reviewing, and designing the topic. $\mathrm{YH}$ contributed to designing the topic, writing, and reviewing. All authors contributed to the article and approved the submitted version.

\section{FUNDING}

This work was supported by the National Natural Science Foundations of China (No. 81601747 to SL and Nos. 31770983 , 81974249 to $\mathrm{DH})$. 
of hematopoietic stem/progenitor cells (HSPCs). Leukemia. (2014) 28:214854. doi: 10.1038/leu.2014.115

9. Verschoor A, Langer HF. Crosstalk between platelets and the complement system in immune protection and disease. Thromb Haemost. (2013) 110:9109. doi: 10.1160/TH13-02-0102

10. Hamad OA, Ekdahl KN, Nilsson PH, Andersson J, Magotti P, Lambris JD, et al. Complement activation triggered by chondroitin sulfate released by thrombin receptor-activated platelets. J Thromb Haemost. (2008) 6:141321. doi: 10.1111/j.1538-7836.2008.03034.x

11. Wiedmer T, Esmon CT, Sims PJ. Complement proteins C5b-9 stimulate procoagulant activity through platelet prothrombinase. Blood. (1986) 68:87580. doi: $10.1182 /$ blood.V68.4.875.bloodjournal684875

12. Polley MJ, Nachman R. The human complement system in thrombin-mediated platelet function. J Exp Med. (1978) 147:171326. doi: $10.1084 /$ jem.147.6.1713

13. Sims PJ, Faioni EM, Wiedmer T, Shattil SJ. Complement proteins C5b-9 cause release of membrane vesicles from the platelet surface that are enriched in the membrane receptor for coagulation factor Va and express prothrombinase activity. J Biol Chem. (1988) 263:18205-12.

14. Sims PJ, Wiedmer T. The response of human platelets to activated components of the complement system. Immunol Today. (1991) 12:33842. doi: 10.1016/0167-5699(91)90012-I

15. Ando B, Wiedmer T, Hamilton KK, Sims PJ. Complement proteins c5b-9 initiate secretion of platelet storage granules without increased binding of fibrinogen or von willebrand factor to newly expressed cell surface gpIIb-IIIa. J Biol Chem. (1988) 263:11907-14.

16. Greer SF, Lin J, Clarke CH, Justement LB. Major histocompatibility class IImediated signal transduction is regulated by the protein-tyrosine phosphatase Cd45. J Biol Chem. (1998) 273:11970-9. doi: 10.1074/jbc.273.19.11970

17. Nunez D, Charriaut-Marlangue C, Barel M, Benveniste J, Frade R. Activation of human platelets through gp140, the C3d/EBV receptor (Cr2). Eur J Immunol. (1987) 17:515-20. doi: 10.1002/eji.1830170413

18. Kolm R, Schaller M, Roumenina LT, Niemiec I, Kremer Hovinga JA, et al. Von willebrand factor interacts with surface-bound $\mathrm{Clq}$ and induces platelet rolling. J Immunol. (2016) 197:3669-79. doi: 10.4049/jimmunol.1501876

19. Peerschke EI, Murphy TK, Ghebrehiwet B. Activation-dependent surface expression of gC1qR/p33 on human blood platelets. Thromb Haemost. (2003) 89:331-9. doi: 10.1055/s-0037-1613450

20. Ekdahl KN, Nilsson B. Alterations in C3 activation and binding caused by phosphorylation by a casein kinase released from activated human platelets. $J$ Immunol. (1999) 162:7426-33.

21. Sims PJ, Wiedmer T. Repolarization of the membrane potential of blood platelets after complement damage: evidence for a ca++ dependent exocytotic elimination of C5b-9 pores. Blood. (1986) 68:55661. doi: 10.1182/blood.V68.2.556.bloodjournal682556

22. Subramaniam S, Jurk K, Hobohm L, Jackel S, Saffarzadeh M, Schwierczek K, et al. Distinct contributions of complement factors to platelet activation and fibrin formation in venous thrombus development. Blood. (2017) 129:2291302. doi: 10.1182/blood-2016-11-749879

23. Peerschke EI, Ghebrehiwet B. Clq augments platelet activation in response to aggregated Ig. J Immunol. (1997) 159:5594-8.

24. Wiedmer T, Hall SE, Ortel TL, Kane WH, Rosse WF, Sims PJ. Complementinduced vesiculation and exposure of membrane prothrombinase sites in platelets of paroxysmal nocturnal hemoglobinuria. Blood. (1993) 82:11926. doi: 10.1182/blood.V82.4.1192.bloodjournal8241192

25. Kansas GS. Selectins and their ligands: current concepts and controversies. Blood. (1996) 88:3259-87. doi: 10.1182/blood.V88.9.3259.bloodjournal88 93259

26. Del Conde I, Cruz MA, Zhang H, Lopez JA, Afshar-Kharghan V. Platelet activation leads to activation and propagation of the complement system. $J$ Exp Med. (2005) 201:871-9. doi: 10.1084/jem.20041497

27. Sprague DL, Elzey BD, Crist SA, Waldschmidt TJ, Jensen RJ, Ratliff TL. Platelet-mediated modulation of adaptive immunity: unique delivery of Cd154 signal by platelet-derived membrane vesicles. Blood. (2008) 111:502836. doi: 10.1182/blood-2007-06-097410

28. Davis AE III, Kenney DM. Properdin factor D: effects on thrombininduced platelet aggregation. J Clin Invest. (1979) 64:721-8. doi: 10.1172/JCI1 09515
29. Ferdous F, Scott TR. A comparative examination of thrombocyte/platelet immunity. Immunol Lett. (2015) 163:32-9. doi: 10.1016/j.imlet.2014.11.010

30. Yin W, Ghebrehiwet B, Peerschke EI. Expression of complement components and inhibitors on platelet microparticles. Platelets. (2008) 19:225-33. doi: 10.1080/09537100701777311

31. Devine DV, Rosse WF. Regulation of the activity of platelet-bound C3 convertase of the alternative pathway of complement by platelet factor H. Proc Natl Acad Sci USA. (1987) 84:5873-7. doi: 10.1073/pnas.84.16.5873

32. Ferluga J, Kishore U, Sim RB. A potential anti-coagulant role of complement factor H. Mol Immunol. (2014) 59:188-93. doi: 10.1016/j.molimm.2014.02.012

33. Licht C, Pluthero FG, Li L, Christensen H, Habbig S, Hoppe B, et al. Plateletassociated complement factor $\mathrm{H}$ in healthy persons and patients with Atypical HUS. Blood. (2009) 114:4538-45. doi: 10.1182/blood-2009-03-205096

34. Noone DG, Riedl M, Pluthero FG, Bowman ML, Liszewski MK, Lu L, et al. Von willebrand factor regulates complement on endothelial cells. Kidney Int. (2016) 90:123-34. doi: 10.1016/j.kint.2016.03.023

35. Hamad OA, Nilsson PH, Lasaosa M, Ricklin D, Lambris JD, Nilsson $B$, et al. Contribution of chondroitin sulfate a to the binding of complement proteins to activated platelets. PLoS ONE. (2010) 5:e12889 doi: 10.1371/journal.pone.0012889

36. Najaoui A, Bakchoul T, Stoy J, Bein G, Rummel MJ, Santoso S, et al. Autoantibody-mediated complement activation on platelets is a common finding in patients with immune thrombocytopenic purpura (ITP). Eur J Haematol. (2012) 88:167-74. doi: 10.1111/j.1600-0609.2011.01718.x

37. Noris M, Mescia F, Remuzzi G. STEC-HUS, Atypical HUS and TTP are all diseases of complement activation. Nat Rev Nephrol. (2012) 8:62233. doi: 10.1038/nrneph.2012.195

38. Jozsi M, Strobel S, Dahse HM, Liu WS, Hoyer PF, Oppermann M, et al. Anti factor $\mathrm{H}$ autoantibodies block c-terminal recognition function of factor H in hemolytic uremic syndrome. Blood. (2007) 110:15168. doi: 10.1182/blood-2007-02-071472

39. Risitano AM. Paroxysmal nocturnal hemoglobinuria and other complement-mediated hematological disorders. Immunobiology. (2012) 217:1080-7. doi: 10.1016/j.imbio.2012.07.014

40. Dixon RH, Rosse WF. Mechanism of complement-mediated activation of human blood platelets in vitro: Comparison of normal and paroxysmal nocturnal hemoglobinuria platelets. J Clin Invest. (1977) 59:360-8. doi: 10.1172/JCI108648

41. Mollnes TE, Garred P, Bergseth G. Effect of time, temperature and anticoagulants on in vitro complement activation: consequences for collection and preservation of samples to be examined for complement activation. Clin Exp Immunol. (1988) 73:484-8.

42. Hess K, Ajjan R, Phoenix F, Dobo J, Gal P, Schroeder V. Effects of MASP-1 of the complement system on activation of coagulation factors and plasma clot formation. PLoS ONE. (2012) 7:e35690. doi: 10.1371/journal.pone.0035690

43. Kozarcanin H, Lood C, Munthe-Fog L, Sandholm K, Hamad OA, Bengtsson AA, et al. The lectin complement pathway serine proteases (MASPs) represent a possible crossroad between the coagulation and complement systems in thromboinflammation. J Thromb Haemost. (2016) 14:53145. doi: $10.1111 /$ jth.13208

44. Gulla KC, Gupta K, Krarup A, Gal P, Schwaeble WJ, Sim RB, et al. Activation of mannan-binding lectin-associated serine proteases leads to generation of a fibrin clot. Immunology. (2010) 129:482-95. doi: 10.1111/j.1365-2567.2009.03200.x

45. Ikeda K, Nagasawa K, Horiuchi T, Tsuru T, Nishizaka H, Niho Y. C5a induces tissue factor activity on endothelial cells. Thromb Haemost. (1997) 77:394-8. doi: 10.1055/s-0038-1655974

46. Ritis K, Doumas M, Mastellos D, Micheli A, Giaglis S, Magotti P, et al. A novel C5a receptor-tissue factor cross-talk in neutrophils links innate immunity to coagulation pathways. J Immunol. (2006) 177:4794802. doi: 10.4049/jimmunol.177.7.4794

47. Wojta J, Kaun C, Zorn G, Ghannadan M, Hauswirth AW, Sperr WR, et al. C5a stimulates production of plasminogen activator inhibitor-1 in human mast cells and basophils. Blood. (2002) 100:517-23. doi: 10.1182/blood.V100.2.517

48. Wojta J, Huber K, Valent P. New aspects in thrombotic research: Complement induced switch in mast cells from a profibrinolytic to a prothrombotic phenotype. Pathophysiol Haemost Thromb. (2003) 33:43841. doi: $10.1159 / 000083842$ 
49. Markiewski MM, Nilsson B, Ekdahl KN, Mollnes TE, Lambris JD. Complement and coagulation: strangers or partners in crime? Trends Immunol. (2007) 28:184-92. doi: 10.1016/j.it.2007.02.006

50. Lupu F, Keshari RS, Lambris JD, Coggeshall KM. Crosstalk between the coagulation and complement systems in sepsis. Thromb Res. (2014) 133(Suppl. 1):S28-31. doi: 10.1016/j.thromres.2014.03.014

51. Ermert D, Blom AM. C4b-binding protein: the good, the bad and the deadly. Novel functions of an old friend. Immunol Lett. (2016) 169:8292. doi: 10.1016/j.imlet.2015.11.014

52. Davis AE III, Mejia P, Lu F. Biological activities of C1 inhibitor. Mol Immunol. (2008) 45:4057-63. doi: 10.1016/j.molimm.2008.06.028

53. Conway EM. Reincarnation of ancient links between coagulation and complement. J Thromb Haemost. (2015) 13(Suppl. 1):S12132. doi: $10.1111 /$ jth. 12950

54. Ghebrehiwet B, Kaplan AP, Joseph K, Peerschke EI. The complement and contact activation systems: partnership in pathogenesis beyond angioedema. Immunol Rev. (2016) 274:281-9. doi: 10.1111/imr.12469

55. Mahdi F, Madar ZS, Figueroa CD, Schmaier AH. Factor XII interacts with the multiprotein assembly of urokinase plasminogen activator receptor, gC1qR, and Cytokeratin 1 on endothelial cell membranes. Blood. (2002) 99:358596. doi: 10.1182/blood.V99.10.3585

56. Dzik S. Complement and coagulation: cross talk through time. Transfus Med Rev. (2019) 33:199-206. doi: 10.1016/j.tmrv.2019.08.004

57. Kaplan AP, Ghebrehiwet B. The plasma bradykinin-forming pathways and its interrelationships with complement. Mol Immunol. (2010) 47:21619. doi: 10.1016/j.molimm.2010.05.010

58. Endo Y, Nakazawa N, Iwaki D, Takahashi M, Matsushita M, Fujita T. Interactions of ficolin and mannose-binding lectin with fibrinogen/fibrin augment the lectin complement pathway. J Innate Immun. (2010) 2:3342. doi: 10.1159/000227805

59. Irmscher S, Doring N, Halder LD, Jo EAH, Kopka I, Dunker C, et al. Kallikrein cleaves C3 and activates complement. J Innate Immun. (2018) 10:94-105. doi: 10.1159/000484257

60. Schmaier AH. The elusive physiologic role of factor XII. J Clin Invest. (2008) 118:3006-9. doi: 10.1172/JCI36617

61. Huber-Lang M, Sarma JV, Zetoune FS, Rittirsch D, Neff TA, McGuire SR, et al. Generation of C5a in the absence of C3: a new complement activation pathway. Nat Med. (2006) 12:682-7. doi: 10.1038/nm1419

62. Feng S, Liang X, Cruz MA, Vu H, Zhou Z, Pemmaraju N, et al. The interaction between factor $\mathrm{H}$ and von willebrand factor. PLoS ONE. (2013) 8:e73715. doi: 10.1371/journal.pone.0073715

63. Turner N, Nolasco L, Nolasco J, Sartain S, Moake J. Thrombotic microangiopathies and the linkage between von willebrand factor and the alternative complement pathway. Semin Thromb Hemost. (2014) 40:54450. doi: 10.1055/s-0034-1383547

64. Heurich M, Preston RJ, O’Donnell VB, Morgan BP, Collins PW. Thrombomodulin enhances complement regulation through strong affinity interactions with factor $\mathrm{H}$ and C3b-factor $\mathrm{H}$ complex. Thromb Res. (2016) 145:84-92. doi: 10.1016/j.thromres.2016.07.017

65. Keizer MP, Pouw RB, Kamp AM, Patiwael S, Marsman G, Hart MH, et al. TFPI inhibits lectin pathway of complement activation by direct interaction with MASP-2. Eur J. Immunol. (2015) 45:544-50. doi: 10.1002/eji.201445070

66. de Bont CM, Boelens WC, Pruijn GJM. Netosis, complement, and coagulation: a triangular relationship. Cell. Mol Immunol. (2019) 16:1927. doi: 10.1038/s41423-018-0024-0

67. Nording H, Langer HF. Complement links platelets to innate immunity. Semin. Immunol. (2018) 37:43-52. doi: 10.1016/j.smim.2018.01.003

68. Berentsen S, Sundic T. Red blood cell destruction in autoimmune hemolytic anemia: role of complement and potential new targets for therapy. Biomed Res Int. (2015) 2015:363278. doi: 10.1155/2015/363278

69. Shi J, Rose EL, Singh A, Hussain S, Stagliano NE, Parry GC, et al. Tnt003, an inhibitor of the serine protease $\mathrm{C} 1 \mathrm{~s}$, prevents complement activation induced by cold agglutinins. Blood. (2014) 123:4015-22. doi: 10.1182/blood-2014-02-556027

70. Baines AC, Brodsky RA. Complementopathies. Blood Rev. (2017) 31:21323. doi: 10.1016/j.blre.2017.02.003

71. Berentsen S. Complement, cold agglutinins, and therapy. Blood. (2014) 123:4010-2. doi: 10.1182/blood-2014-04-568733
72. Yang R, Huang J, Ma H, Li S, Gao X, Liu Y, et al. Is complement C1q a potential marker for tumor burden and immunodeficiency in multiple myeloma? Leuk Lymphoma. (2019) 60:1812-8. doi: 10.1080/10428194.2018.1543883

73. Mamidi S, Hone S, Teufel C, Sellner L, Zenz T, Kirschfink M. Neutralization of membrane complement regulators improves complement-dependent effector functions of therapeutic anticancer antibodies targeting leukemic cells. Oncoimmunology. (2015) 4:e979688. doi: 10.4161/2162402X.2014.979688

74. Johnsen J. Pathogenesis in immune thrombocytopenia: new insights. Hematol Am Soc Hematol Educ Program. (2012) 2012:306-12. doi: 10.1182/asheducation.V2012.1.306.3798320

75. Takahashi K, Chang WC, Takahashi M, Pavlov V, Ishida Y, La Bonte L, et al. Mannose-binding lectin and its associated proteases (MASPs) mediate coagulation and its deficiency is a risk factor in developing complications from infection, including disseminated intravascular coagulation. Immunobiology. (2011) 216:96-102. doi: 10.1016/j.imbio.2010.02.005

76. Zhao X, Chen YX, Li CS. Predictive value of the complement system for sepsis-induced disseminated intravascular coagulation in septic patients in emergency department. J Crit Care. (2015) 30:290-5. doi: 10.1016/j.jcrc.2014.11.007

77. Korkama ES, Armstrong AE, Jarva H, Meri S. Spontaneous remission in paroxysmal nocturnal hemoglobinuria-return to health or transition into malignancy? Front Immunol. (2018) 9:1749. doi: 10.3389/fimmu.2018.01749

78. Ruiz-Arguelles A, Llorente L. The role of complement regulatory proteins (Cd55 and Cd59) in the pathogenesis of autoimmune hemocytopenias. Autoimmun Rev. (2007) 6:155-61. doi: 10.1016/j.autrev.2006.09.008

79. Ronne E, Pappot H, Grondahl-Hansen J, Hoyer-Hansen G, Plesner T, Hansen NE, et al. The receptor for urokinase plasminogen activator is present in plasma from healthy donors and elevated in patients with paroxysmal nocturnal haemoglobinuria. Br J Haematol. (1995) 89:57681. doi: 10.1111/j.1365-2141.1995.tb08366.x

80. Maroney SA, Cunningham AC, Ferrel J, Hu R, Haberichter S, Mansbach CM, et al. A GPI-anchored co-receptor for tissue factor pathway inhibitor controls its intracellular trafficking and cell surface expression. J Thromb Haemost. (2006) 4:1114-24. doi: 10.1111/j.1538-7836.2006.01873.x

81. Hillmen P, Muus P, Duhrsen U, Risitano AM, Schubert J, Luzzatto L, et al. Effect of the complement inhibitor eculizumab on thromboembolism in patients with paroxysmal nocturnal hemoglobinuria. Blood. (2007) 110:41238. doi: 10.1182/blood-2007-06-095646

82. Frimat M, Tabarin F, Dimitrov JD, Poitou C, Halbwachs-Mecarelli L, Fremeaux-Bacchi V, et al. Complement activation by heme as a secondary hit for atypical hemolytic uremic syndrome. Blood. (2013) 122:28292. doi: 10.1182/blood-2013-03-489245

83. Fakhouri F, Zuber J, Fremeaux-Bacchi V, Loirat C. Haemolytic uraemic syndrome. Lancet. (2017) 390:681-96. doi: 10.1016/S0140-6736(17)30062-4

84. Skerka C, Licht C, Mengel M, Uzonyi B, Strobel S, Zipfel PF, et al. Autoimmune forms of thrombotic microangiopathy and membranoproliferative glomerulonephritis: indications for a disease spectrum and common pathogenic principles. Mol Immunol. (2009) 46:2801-7. doi: 10.1016/j.molimm.2009.05.018

85. Jozsi M, Licht C, Strobel S, Zipfel SL, Richter H, Heinen S, et al. Factor $\mathrm{H}$ autoantibodies in atypical hemolytic uremic syndrome correlate with CFHR1/CFHR3 deficiency. Blood. (2008) 111:1512-4. doi: 10.1182/blood-2007-09-109876

86. Neumann HP, Salzmann M, Bohnert-Iwan B, Mannuelian T, Skerka C, Lenk $\mathrm{D}$, et al. Haemolytic uraemic syndrome and mutations of the factor $\mathrm{H}$ gene: a registry-based study of German speaking countries. J Med Genet. (2003) 40:676-81. doi: 10.1136/jmg.40.9.676

87. Roumenina LT, Jablonski M, Hue C, Blouin J, Dimitrov JD, Dragon-Durey $\mathrm{MA}$, et al. Hyperfunctional C3 convertase leads to complement deposition on endothelial cells and contributes to atypical hemolytic uremic syndrome. Blood. (2009) 114:2837-45. doi: 10.1182/blood-2009-01-197640

88. Abarrategui-Garrido C, Martinez-Barricarte R, Lopez-Trascasa M, de Cordoba SR, Sanchez-Corral P. Characterization of complement factor $\mathrm{H}$ related (CFHR) proteins in plasma reveals novel genetic variations of CFHR1 associated with atypical hemolytic uremic syndrome. Blood. (2009) 114:426171. doi: 10.1182/blood-2009-05-223834

89. Zipfel PF, Edey M, Heinen S, Jozsi M, Richter H, Misselwitz J, et al. Deletion of complement factor H-related genes CFHR1 and CFHR3 is 
associated with atypical hemolytic uremic syndrome. PLoS Genet. (2007) 3:e41 doi: 10.1371/journal.pgen.0030041

90. Barnum SR. Complement: A primer for the coming therapeutic revolution. Pharmacol Ther. (2017) 172:63-72. doi: 10.1016/j.pharmthera.2016.11.014

91. Cofiell R, Kukreja A, Bedard K, Yan Y, Mickle AP, Ogawa M, et al. Eculizumab reduces complement activation, inflammation, endothelial damage, thrombosis, and renal injury markers in ahus. Blood. (2015) 125:3253-62. doi: 10.1182/blood-2014-09-600411

92. Peerschke EI, Panicker S, Bussel J. Classical complement pathway activation in immune thrombocytopenia purpura: inhibition by a novel C1s inhibitor. Br J Haematol. (2016) 173:942-5. doi: 10.1111/bjh.13648

93. Zeerleder S. C1-inhibitor: More than a serine protease inhibitor. Semin Thromb Hemost. (2011) 37:362-74. doi: 10.1055/s-0031-1276585

94. Risitano AM, Ricklin D, Huang Y, Reis ES, Chen H, Ricci P, et al. Peptide inhibitors of C3 activation as a novel strategy of complement inhibition for the treatment of paroxysmal nocturnal hemoglobinuria. Blood. (2014) 123:2094-101. doi: 10.1182/blood-2013-11-536573

95. Risitano AM, Notaro R, Pascariello C, Sica M, del Vecchio L, Horvath $\mathrm{CJ}$, et al. The complement receptor 2 /factor $\mathrm{H}$ fusion protein TT30 protects paroxysmal nocturnal hemoglobinuria erythrocytes from complement-mediated hemolysis and C3 fragment. Blood. (2012) 119:6307-16. doi: 10.1182/blood-2011-12-398792

96. Qiao Q, Teng X, Wang N, Lu R, Guo L, Zhang X, et al. A novel CRIg-targeted complement inhibitor protects cells from complement damage. FASEB J. (2014) 28:4986-99. doi: 10.1096/fj.14-258046
97. Lindorfer MA, Pawluczkowycz AW, Peek EM, Hickman K, Taylor RP, Parker CJ. A novel approach to preventing the hemolysis of paroxysmal nocturnal hemoglobinuria: both complement-mediated cytolysis and C3 deposition are blocked by a monoclonal antibody specific for the alternative pathway of complement. Blood. (2010) 115:2283-91. doi: 10.1182/blood-2009-09-2 44285

98. Lee JW, Sicre de Fontbrune F, Wong Lee Lee L, Pessoa V, Gualandro S, Fureder W, et al. Ravulizumab (ALXN1210) vs eculizumab in adult patients with PNH naive to complement inhibitors: the 301 study. Blood. (2019) 133:530-9. doi: 10.1182/blood-2018-09-876136

99. Hill A, Kelly RJ, Hillmen P. Thrombosis in paroxysmal nocturnal hemoglobinuria. Blood. (2013) 121:4985-96; quiz 5105. doi: 10.1182/blood-2012-09-311381

Conflict of Interest: The authors declare that the research was conducted in the absence of any commercial or financial relationships that could be construed as a potential conflict of interest.

Copyright (c) $2020 \mathrm{Luo}, \mathrm{Hu}$, Wang, Zipfel and Hu. This is an open-access article distributed under the terms of the Creative Commons Attribution License (CC BY). The use, distribution or reproduction in other forums is permitted, provided the original author(s) and the copyright owner(s) are credited and that the original publication in this journal is cited, in accordance with accepted academic practice. No use, distribution or reproduction is permitted which does not comply with these terms. 